\title{
ПРОДВИЖЕНИЕ ЗАКОНОВ С КОНТРАДИКТОРНЫМИ ФУНКЦИЯМИ
}

\begin{abstract}
Аннотация: В статье обосновывается необходимость продвижения законов, имеющих контрадикторные функции. Такими законами являются те, которые имеют целью ликвидацию и формирование в обществе отночений, противоречащих его менталитету. К таким законам, как правило, относятся те, в которых воплощается опыт зарубежных государства. Их реализачия встречает сопротивление общества. Для того, чтобы такие законы были эффективными необходимо проявление политической воли государства с иелью продвижения их в обществе. Такое продвижение должно начинаться на начальной стадии законотворческой деятельности и продолжаться после принятия закона до достижения цели его принятия. Под продвижением законов понимается комплекс государственных мер, направленных на разъяснение их смысла, убеждение в их необходимости для общества, на принуждение («мягкое» или «жесткое») их исполнения. Стратегия такого продвижения может быть заложена в концепџии закона, которая разрабатывается субъектом законодательной инициативы, а также в плане мероприятий по реализации закона.

Review: The article provides the grounds for the need to promote the law with contradictory functions, that is the laws aimed to liquidate and form the social relations, contradicting its mentality. Mostly, such laws include those based upon the experience of the foreign states. Their implementation faces social opposition. In order for such laws to be efficient, the political will of the state should be expressed in order to promote them in a society. Such a promotion should start at the primary legislative stage and continue till the goals of such a law are achieved. Promotion of laws is understood as a complex of state measures aimed at explaining the meaning of such laws, convincing that such laws are a necessity, coercion (soft or hard) in order to guarantee compliance. A strategy for such promotion may be included within the concept of a law, as developed by a subject of legislative initiative, or within the framework of measures for its implementation.
\end{abstract}

Ключевые слова: контрадикторные функиии, контрадикторные законы, концепция законопроекта, реализации федеральных законов, продвижение законов, правовой менталитет, Общественная палата, государственное принуждение, законопроектная деятельность, закон о правотворчестве

Keywords: contradictory functions, contradictory laws, concept of the legislative draft, implementation of federal laws, promotion of laws, legal mentality, the Public Chamber, state coercion, legislative activity, law on law-making.

аконы, которые имеют целью изменения, формирования новых и ликвидацию существующих общественных отношений, обладают контрадикторными ${ }^{1}$ функциями, которые воздействуют на общество в противоположных направлениях, чем направления воздействия его интегрального менталитета. Выделение таких функций и законов имеет практическое значение. Принятие и реализация законов с контрадикторными функциями должны сопровождаться стратегией их продвижения для преодоления сопротивления общества, обладающего определенными ментальными константами.

\footnotetext{
${ }^{1}$ Контрадикторный от лат. contrādictōrius противоречащий, опро-
} вергающий.
Условия современной жизни диктуют необходимость формирования в обществе новых для него отношений, новых ментальных констант. Сделать это сложно на протяжении жизни одного поколения людей. Право может воздействовать только на общественное сознание, часть которого составляет «осознанную» часть менталитета. Если государство заинтересовано в установлении новых отношений в обществе, при воздействии на общественное сознание оно должно проявить политическую волю, направленную на преодоление конфликта между правом и ментальными установками. Твёрдая политическая воля будет стимулировать адаптационные силы общества, постепенно изменяя общественное сознание, в том числе и ту часть, которая является частью менталитета. 
DOI: 10.7256/1811-9018.2013.9.9360

При цитировании этой статьи сноска на dоі обязательна

\section{Право и политика 9 (165) • 2013}

Изменение общественного сознания с целью формирования новых стабильных отношений во многом обеспечивается правовыми традициями, стереотипами мышления и т.п., которые позволяют обществу формировать чувство уверенности в завтрашнем дне, дают возможность предвидеть положительные последствия реализации правовых норм. Более того, формирование правовых традиций позволит обеспечить стабильность нормативно-правовых актов.

Политическая воля государства в формировании новых отношений в обществе связана не только с применением принуждения. Убеждение и разъяснение также могут стать действенными инструментами изменения отношений в обществе, формирования новых желаемых традиций, идей, стереотипов и т.п.

Комплекс государственных мер, связанных с принятием законов, направленных на разъяснение их смысла, убеждение в их полезной для общества необходимости, на принуждение («мягкое»или «жесткое») их исполнения и т.п., можно назвать «продвижением законов».

Процесс продвижения законов с целью разъяснения и убеждения общества в их целесообразности и полезности, а также принуждения должен быть сформирован стратегически. Думается, что правильная стратегия продвижения законов позволит подтолкнуть изменение общественного сознания. Действительно, общество должно быть подготовлено к формированию новых отношений, время такой подготовки не может не сократиться от продуманного воздействия на общественное сознание.

Разъяснение идеи закона является важной составной частью воздействия на общественное сознание индивидов. Результатом разъяснения должно стать уяснение обществом идеи закона. Для того чтобы эта идея была воплощена в жизнь необходимо, чтобы члены общества понимали общественную и личную полезность реализации его норм. В том случае, если государство нуждается в формировании новых отношений в обществе больше, чем его члены, то должны быть продуманы меры государственного принуждения общества действовать определенным образом. Такое принуждение может быть осуществлено через правовые нормы.

Готовность общества воспринимать изменения, обусловленные принятием новых норм права, обусловливается свойством общества, которое принято сейчас называть «правовым менталитетом».
Понимание законодательными органами и иными субъектами права сущности правового менталитета народа сделает их юридически значимыми действия обоснованными и поддерживаемыми со стороны общества. Это мнение разделяется исследователями правового менталитета ${ }^{2}$.

Действия государственной власти, не соответствующие менталитету, могут оказаться без поддержки общества, и государство вынуждено будет преодолевать дополнительное сопротивление масс, сомневающихся в полезности грядущих перемен.

Учитывая вышеизложенное, можно сделать вывод, что субъекту законодательной инициативы (прежде всего), организациям, обеспечивающим его исполнение, законодателям требуется информация об особенностях менталитета общества на государственно-правовом пространстве при принятии законов с контрадикторными функциями. Источниками информации могут стать как научные организации, комплексно изучающие менталитет, организации гражданского общества, организации, проводящие социологические опросы и др.

Одной из таких организаций в Российской Федерации может стать Общественная палата Российской Федерации, которая обеспечивает взаимодействие граждан, общественных объединений с федеральными органами государственной власти, органами государственной власти субъектов и органами местного самоуправления в целях учета потребностей и интересов граждан Российской Федерации ${ }^{3}$.

Подобные органы существуют и в других государствах. Например, наиболее эффективный - это французское общественное собрание. Они делают не просто экспертизу законопроектов, но и, по сути, формируют общественное мнение. В частности, ярким примером, является законопроект о хиджабах. Общественное собрание Франции в течение полутора лет внедряло в массы идею и целесообразность этого закона, и в итоге: только два человека во всей Франции, две семьи послали детей в школу в хиджабах. Потом оказалось,

\footnotetext{
${ }^{2}$ См.: Байниязов Р.С. Правосознание и правовой менталитет в России: дис. ...д-ра юрид. наук: 12.00.01. Саратов, 2006. С.115; Меняйло Д.В. Правовой менталитет: дис. ...канд. юрид. наук: 12.00.01. Ростов-н/Д, 2003. С.34.

${ }^{3}$ См.: Об общественной палате Российской Федерации: федер. закон Рос. Федерации от 4 апреля 2005 г. № 32-Ф3 в ред. федер. закона Рос. Федерации от 23 июля 2013 г. № 235-Ф3 // Рос. газ. 2005. - 7 апреля.
} 
DOI: $10.7256 / 1811-9018.2013 .9 .9360$

При цитировании этой статьи сноска на dоі обязательна

Общественные коммуникации

что они просто не знали, что это уже нельзя, и инцидент был исчерпан, и конфликта не было 4 .

Государство, стремящееся к установлению государственного порядка, обладает монополией на принуждение 5 . Принуждение - важнейший элемент публичной власти, о чем писал еще в свое время Н.М. Коркунов: «принудительное властвование, являющееся основным признаком государственного общения, определяет собою все особенности государственного порядка» ${ }^{6}$. Принуждение может быть очевидным и неочевидным ${ }^{7}$. Принуждение не отрицает убеждение. В доктрине права соотношение существуют различные точки зрения на соотношение принуждения и убеждения.

В соответствии с действующим российским законодательством к документам, которые могут обеспечить продвижение закона, могут быть отнесены: 1) концепция законопроекта, 2) план мероприятий по реализации федерального закона.

Концепция законопроекта является одним из возможных документов, который предшествует разработке законопроекта. В соответствии с п.4 Положения о законопроектной деятельности Правительства Российской Федерации, утв. Постановлением правительства от 30 апреля 2009 г. № $389^{8}$ он по решению Комиссии Правительства Российской Федерации по законопроектной деятельности может быть необходимым для включения проекта федерального закона в правительственный план законопроектной деятельности. При этом упомянутое Положение не определяет, в каких случаях Комиссия принимает такое решение. Было бы правильным, нормативно закрепить обязательное требование предоставления концепции при разработке законов, обладающих контрадикторными функциями.

\footnotetext{
${ }^{4}$ Президентские реформы: взгляд со стороны. Интервью с М. А. Диановым, директором Института региональных проблем. 13 сентября 2005 г. // Всероссийский центр изучения общественного мнения [сайт]. URL: http://wciom.ru/index. php?id=266\&uid $=1698$.

${ }_{5}^{5}$ Тихомиров Ю.А. Публичное право: учебник. М.: Изд-во «БЕК», 1995. C. $168-169$.

${ }^{6}$ Коркунов Н.М. Русское государственное право: в 2 т. Т.1. СПб, 1892. C. 4-5.

${ }^{7}$ Моисеев С.В. Философия права. Новосибирск: Сибирское университетское издательство, 2003. С.12.

${ }^{8}$ См.: Собр. законодательства Рос. Федерации. - 2009. - 11 мая.
} - № 19. - Ст. 2346.
Концепция проекта федерального закона обсуждается в первом чтении рассмотрения законопроекта и является основанием для его принятия.

Основные требования, предъявляемые к ней, закреплены в Постановлении Правительства РФ от 2 августа 2001 г. № 576 «Об утверждении Основных требований к концепции и разработке проектов федеральных законов ${ }^{9}$. В соответствии с п.3 этого Постановления концепция законопроекта представляет собой документ, в котором должны быть определены: 1) основная идея, цели и предмет правового регулирования, круг лиц, на которых распространяется действие законопроекта, их новые права и обязанности, в том числе с учетом ранее имевшихся; 2) место будущего закона в системе действующего законодательства с указанием отрасли законодательства, к которой он относится, положений Конституции Российской Федерации, федеральных конституционных законов и системообразующих законов Российской Федерации, на реализацию которых направлен данный законопроект, а также значение, которое будет иметь законопроект для правовой системы; 3) общая характеристика и оценка состояния правового регулирования соответствующих общественных отношений с приложением анализа действующих в этой сфере законов и иных нормативных правовых актов. При этом указываются пробелы и противоречия в действующем законодательстве, наличие устаревших норм права, фактически утративших силу, а также неэффективных положений, не имеющих должного механизма реализации, рациональные и наиболее эффективные способы устранения имеющихся недостатков правового регулирования. Общая характеристика состояния правового регулирования должна также содержать анализ соответствующей российской и зарубежной правоприменительной практики, а также результаты проведения статистических, социологических и политологических исследований; 4) социально-экономические, политические, юридические и иные последствия реализации будущего закона.

Из приведенного перечня требований к концепции проекта закона очевидно, что уже на начальной стадии разработки закона определяется круг лиц (субъектов), на которые он будет распространен. Следовательно, уже в концепции возможно определить, направлен ли новый закон на закрепление, изменение, ликвидацию или формирование но-

\footnotetext{
${ }^{9}$ См.: Рос. газ. - 2001. - 9 августа. - № 151 - 152.
} 


\section{Право и политика 9 (165) • 2013}

вых отношений в обществе, в которое такие лица входят. Тем не менее, существующие требования к концепции направлены только на выяснение соответствия норм будущего закона фактически сложившимся отношениям. Этому способствует выявление пробелов и устаревших (фактически утративших силу) норм права. Такой подход не способствует продвижению законов, имеющих контрадикторные функции, которые имеют целью ликвидацию, изменение существующих или формирование новых отношений в обществе.

Не способствует продвижению таких законов и требование наличия в концепции указания на неэффективные положения действующего законодательства, не имеющих должного механизма реализации, поскольку оно не устанавливает требования определения причин такой неэффективности. Ими могут быть и несоответствие функций закона функциям менталитета, которые необходимо учитывать при принятии законов. На это обращали внимание и другие авторы. Так, например, В. Баранов, который анализировал негативные факторы, связанные с подготовкой и принятием концепции законопроекта и которые через этот элемент законотворческого процесса могут при определенных условиях замедлить, понизить результативность принимаемого закона, пишет: «При создании концепции законопроекта следует учитывать реальные правовые позиции, ориентации и психологические установки тех субъектов, деятельность которых предполагается подвергнуть правовой регламентации. Опираться при этом желательно на данные крупных и долговременных социологических исследований. При подготовке концепций законопроектов социологические исследования должны быть обязательным элементом ее обоснования» ${ }^{10}$.

Несмотря на существующее требование включать в концепцию законопроекта результаты проведения статистических, социологических и политологических исследований, практика показывает, что оно исполняется не всегда ${ }^{11}$, а если

\footnotetext{
${ }^{10}$ Баранов В.M. Концепция законопроекта и ее роль в повышение эффективности принятия закона. URL: http://o-patriotizme.narod. ru/zak_deyatGD2003_konfer_konz.htm.

${ }^{11}$ См.: Об организации дорожного движения и о внесении изменений в отдельные законодательные акты Российской Федерации: концепция проекта Федер. закона // Рос. газ. [сайт]. URL: http:// www.rg.ru/2009/09/02/koncepciya-site.html.
}

исполняется, то не с целью определения нужности обществу соответствующего закона, соответствия его менталитету. Даже если в концепции законопроекта и делаются выводы социологического характера, то не указывается их основание (способ проведения исследования, дата, место, количество респондентов и т.п. $)^{12}$.

Анализ соответствующей российской и зарубежной правоприменительной практики мог бы стать одним из способов определения соответствия принимаемого закона ментальным константам и потребности общества. При этом анализ должен включать сравнение российской и зарубежной практики, а в случае ее расхождения объяснение причин этого.

В законопроектной практике РФ все же встречаются концепции законопроектов, в которых определяются ментальные особенности российского общества. К ним относится, например, Концепция проекта федерального закона «О добровольной пожарной охране» ${ }^{13}$. В ней в результате сравнения практики добровольчества в США и России был сделан следующий вывод, что в России у граждан негативное отношение к волонтерскому труду.

Разработчики концепции считают, что непопулярность добровольчества в России в настоящее время во многом сдерживается несовершенством правовой основы и отсутствием законодательно установленных соответствующих стимулов, льгот и преимуществ для граждан, добровольно участвующих в деятельности по профилактике и тушению пожаров, что может быть преодолено принятием Федерального закона «О добровольной пожарной охране». Не ставя значимость последнего вывода под сомнение, представляется, что он отражает ситуацию поверхностно. Необходимо не только устанавливать стимулы, льготы, преимущества для добровольцев, но и формировать добровольческие традиции, уважительное отношение к ним, а это невозможно только законодательными мерами. Для этого необходима особая программа продвижения закона.

\footnotetext{
${ }^{12}$ См.: О федеральной контрактной системе: концепция проекта Федер. закона // Рос. газ. [сайт]. URL: http://www.rg.ru/2009/09/02/ koncepciya-site.html.

${ }^{13} \mathrm{O}$ добровольной пожарной охране: концепция проекта Федер. закона // Рос. газ. [сайт]. URL: http://www.rg.ru/2009/09/02/ koncepciya-site.html.
} 
Такой программой и логическим продолжением Концепции мог бы стать план мероприятий по реализации федерального закона, принимаемый соответствующим органом исполнительной власти.

План мероприятий по реализации федерального закона является документом, предусмотренным ведомственными документами органов исполнительной власти, в чью компетенцию входит обеспечение реализации закона. Так, например, в соответствии с Приказом Федеральной таможенной службы России от 10 апреля 2008 №396 «О регламенте организации законопроектной работы Федеральной таможенной службы» ${ }^{14}$. В целях организации эффективного исполнения федерального закона Федеральная таможенная служба России осуществляет подготовку и внесение в Правительство Российской Федерации проектов нормативных правовых актов Президента Российской Федерации и Правительства Российской Федерации, обеспечивающих действие норм федерального закона, организует проведение иных необходимых мероприятий. Проанализировав положения раздела $\mathrm{V}$ «Деятельность ФТС России по организации исполнения принимаемых федеральных законов» можно сделать вывод, что основным средством, направленным на исполнение закона, то есть средством продвижения закона, является нормативно-правовой акт, который должен быть изменен или принят с этой целью. Представляется, что для продвижения контрадикторных законов, нормы которых регулируют и частные и публичные отношения, должно сопровождаться применением и иных средств (например: агитации, разьяснение, проведение массовых мероприятий и др.).

Таким образом, очевидно, что в Российской Федерации нет достаточной нормативной базы для продвижения законов с контрадикторными функциями. Такой недостаток может быть преодолен либо принятием закона о правотворчестве, о необходимости которого неоднократно писалось, либо внесением изменений в действующие нормативно-правовые акты, регулирующие соответствующую деятельность органов, которые обладают законодательной инициативой. При этом необходимо учитывать, что в России усилия государ-

${ }^{14}$ См.: Таможенные ведомости. - 2008. - № 6. ства, направленные на изменение общественных отношений, должны быть особенно продуманные, поскольку как отмечают исследователи «особое отношение народа к власти, выразившееся, с одной стороны, в сокрализации носителей власти, а с другой - в неприятии многих государственных установлений, правовом нигилизме» ${ }^{15}$.

\section{Библиография:}

1. Байниязов Р.С. Правосознание и правовой менталитет в России: дис. ...д-ра юрид. наук: 12.00.01. Саратов, 2006. 349 c.

2. Баранов В.М. Концепция законопроекта и ее роль в повышение эффективности принятия закона. URL: http://o-patriotizme.narod.ru/zak_deyatGD2003_konfer_konz.htm (дата обращения 10.08.2013).

3. Коркунов Н.М. Русское государственное право: в 2 т. Т.1. СПб, 1892. 402 c.

4. Меняйло Д.В. Правовой менталитет: дис. ...канд. юрид. наук: 12.00.01. Ростов-н/Д, 2003. 189 с.

5. Моисеев С.В. Философия права. Новосибирск: Сибирское университетское издательство, 2003. $203 \mathrm{c}$.

6. Об общественной палате Российской Федерации: федер. закон Рос. Федерации от 4 апреля 2005 г. № 32-Ф3 (в ред. от 30.12.2012 г.) принят Гос. Думой Федер. Собр. Рос. Федерации 16 марта 2005 г.: одобрен Советом Федерации Федер. Собр. Рос. Федерации 23 марта 2005 г. // Рос. газ. - 2005. - 7 апреля.

7. О добровольной пожарной охране: концепция проекта федер. закона // Российская газета [сайт]. URL: http://www.rg.ru/2009/09/02/ koncepciya-site. html (дата обращения 10.08.2013).

8. Об организации дорожного движения и о внесении изменений в отдельные законодательные акты Российской Федерации: концепция проекта Федер. закона // Российская газета [сайт]. URL: http://www. rg.ru/2009/09/02/koncepciya-site.html (дата обращения 10.08.2013).

9. Об утверждении Основных требований к концепции и разработке проектов федеральных законов: постановление Правительства Рос. Федерации от

\footnotetext{
${ }^{15}$ См.: Цигвинцева Г.Л. Особенности формирования и функционирования менталитета русского народа: дис. ... канд. филос. наук: 09.00.11. Пермь, 2005. С. 21.
} 
DOI: $10.7256 / 1811-9018.2013 .9 .9360$

При цитировании этой статьи сноска на dоі обязательна

\section{Право и политика $9(165) \cdot 2013$}

2 августа 2001 г. № 576 // Российская газета. - 2001.

- 9 августа. - № $151-152$.

10. О федеральной контрактной системе: концепция проекта Федер. закона // Российская газета [сайт]. URL: http://www.rg.ru /2009/09/02/koncepciya-site. html (дата обращения 10.08.2013).

11. Президентские реформы: взгляд со стороны. Интервью с М. А. Диановым, директором Института региональных проблем. 13 сентября 2005 г. // Всероссийский центр изучения общественного мнения [сайт]. URL: http:/wciom.ru/index. php?id=266\&uid=1698 (дата обращения 22.03.2013).

12. Тихомиров Ю.А. Публичное право: учебник. М.: Изд-во «БЕК», 1995. 496 с.

13. Цигвинцева Г.Л. Особенности формирования и функционирования менталитета русского народа: дис. ... канд. филос. наук: 09.00.11. Пермь, 2005. 173 с.

14. Положение о законопроектной деятельности Правительства Рос. Федерации, утв. Постановлением Правительства Рос. Федерации от 30 апреля 2009 г. № 389 // Собр.законодательства Рос. Федерации. - 2009. - 11 мая. - № 19. - Ст. 2346.

15. О регламенте организации законопроектной работы Федеральной таможенной службы: приказ
Федер. таможенной службы России от 10 апреля 2008 № 396 // Таможенные ведомости. - 2008. - № 6.

\section{References (transliteration):}

1. Bayniyazov R.S. Pravosoznanie i pravovoy mentalitet v Rossii: dis. ...d-ra yurid. nauk: 12.00.01. Saratov, 2006. 349 s.

2. Baranov V.M. Koncepciya zakonoproekta i ee rol' v povyshenie effektivnosti prinyatiya zakona. URL: http://o-patriotizme.narod.ru/zak_deyatGD2003_konfer_konz.htm (data obrascheniya 10.08.2013).

3. Korkunov N.M. Russkoe gosudarstvennoe pravo: v 2 t. T.1. SPb, 1892. 402 s.

4. Menyaylo D.V. Pravovoy mentalitet: dis....kand. yurid. nauk: 12.00.01. Rostov-n/D, 2003. $189 \mathrm{~s}$.

5. Moiseev S.V. Filosofiya prava. Novosibirsk: Sibirskoe universitetskoe izdatel'stvo, 2003. 203 s.

6. Tihomirov Yu.A. Publichnoe pravo: uchebnik. M.: Izd-vo «BEK», 1995. $496 \mathrm{~s}$.

7. Cigvinceva G.L. Osobennosti formirovaniya i funkcionirovaniya mentaliteta russkogo naroda: dis. ... kand. filos. nauk: 09.00.11. Perm', 2005. 173 s. 